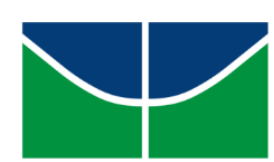

Universidade de Brasília

Faculdade de Ciências da Saúde

Departamento de Enfermagem

Graduação em Enfermagem

ARIELLA GALIZA DE FREITAS

\title{
A EXPERIÊNCIA DA PARENTALIDADE NA SITUAÇÃO DE SÍNDROME NEFRÓTICA DA CRIANÇA
}

Brasília 


\title{
A EXPERIÊNCIA DA PARENTALIDADE NA SITUAÇÃO DE SÍNDROME NEFRÓTICA DA CRIANÇA
}

\begin{abstract}
Trabalho de Conclusão de Curso submetido ao curso de graduação em Enfermagem da Faculdade de Ciências da Saúde (FS) da Universidade de Brasília (UnB), como requisito necessário para a obtenção do título de Bacharel em Enfermagem.
\end{abstract}

Orientadora: Prof ${ }^{a}$. Dra. Aline Oliveira Silveira.

Brasília 
ARIELLA GALIZA DE FREITAS

\section{A EXPERIÊNCIA DA PARENTALIDADE NA SITUAÇÃO DE SÍNDROME NEFRÓTICA DA CRIANÇA}

Trabalho de Conclusão de Curso submetido ao curso de graduação em Enfermagem da Faculdade de Ciências da Saúde (FS) da Universidade de Brasília (UnB), como requisito necessário para a obtenção do título de Bacharel em Enfermagem.

Data de Aprovação: Brasília - DF, de de

\section{BANCA EXAMINADORA}

Dra. Aline Oliveira Silveira

(Orientador - Universidade de Brasília)

Ma. Cristiane Feitosa Salviano

(Membro Efetivo 1 - Universidade de Brasília)

Dra. Gisele Martins

(Membro Efetivo 2 - Universidade de Brasília)

Ma. Mariana Franzoi

(Membro Suplente - Universidade de Brasília) 
Dedico este trabalho ao meu pai Carlos Antônio de Freitas e minha mãe Simone Galiza de Lima, que sempre lutaram para que eu tivesse as melhores das oportunidades, a minha avó Geralda Galiza de Lima, que sempre me emprestou seu colo em momentos de desespero e aos meus irmãos. 


\section{AGRADECIMENTOS}

Agradeço a Deus por sempre ter sido meu guia e luz viva nos momentos sombrios e por ter me dado forças para superar as dificuldades e chegado aqui.

A Prof ${ }^{a} \operatorname{Dr}^{a}$ Aline Silveira pela orientação, apoio e confiança durante 4 longos anos, pelo empenho dedicado à elaboração deste trabalho e por ter me ajudado a descobrir uma nova paixão: a pesquisa científica.

Aos profissionais que me acolheram durante a jornada dessa pesquisa e que permitiram que a mesma tivesse êxito.

Aos meus pais, pelo amor, incentivo e apoio incondicional, por sempre terem feito o possível e impossível para que eu pudesse chegar aonde estou. E a minha família que sempre entendeu meus momentos de ausência para que pudesse realizar a elaboração deste.

Ao Matheus Siqueira Cesar Queiroga, que sempre me incentivou a continuar, mesmo quando os obstáculos eram maiores do que eu mesma, por ter me escutado falar sobre a temática dessa pesquisa por horas a fio e pela ajuda prestada durante todo o processo de construção deste.

A minha irmã Ingrid Galiza de Freitas, que me apoiou e me ajudou durante a graduação e na construção desse.

A Bruna Tavares Albuquerque Cunha, querida amiga, por sempre ter compreendido o motivo da minha ausência e distanciamento, mas nunca ter me deixado.

A minha psicóloga por ter me ajudado a me superar.

E a todos os colegas de graduação, que fizeram parte do meu crescimento profissional e pessoal. 
"Quando uma criatura humana desperta para um grande sonho e sobre ele lança toda a força de sua alma, todo o universo conspira a seu favor."

(Johann Goethe) 


\section{Resumo}

Introdução: A Síndrome Nefrótica (SN) é a manifestação de diferentes doenças glomerulares caracterizada por proteinúria, edema, hipoalbuminemia e hiperlipidemia. O diagnóstico, o tratamento e as complicações associadas têm repercussões na vida da criança e no sistema familiar, exigindo um alto nível de ajustamento social, emocional e físico. A condição de cronicidade da criança constitui uma experiência de transição parental que implica em conviver com constantes mudanças nas atividades da vida diária. Na situação de ter um filho com síndrome nefrótica, a parentalidade é influenciada e a doença é um fator de estresse. Assim, o objetivo do estudo foi: compreender as experiências de parentalidade na situação de síndrome nefrótica da criança. Metodologia: Estudo transversal de abordagem qualitativainterpretativa desenvolvido com pais e mães de crianças portadoras de Síndrome Nefrótica. Os dados foram coletados utilizando-se a técnica de entrevista aberta em profundidade. De forma complementar a entrevista, foi realizada a construção do genograma e o ecomapa da família. Os dados foram analisados por meio do referencial metodológico da Pesquisa de Narrativas e a interpretação foi sustentada pelo referencial teórico do Interacionismo Simbólico. Resultados: Participaram do estudo 8 mães e um pai de crianças com Síndrome Nefrótica. As principais características familiares foram: famílias nucleares (compostas por mãe, pai e filhos); pais com grau de escolaridade ensino fundamental incompleto; e posição da criança com SN na família, em grande parte dos casos é o filho mais novo e com descoberta da doença em média aos 3 anos de idade. A análise das narrativas permitiu a identificação de categorias temáticas representativas das definições da parentalidade, das crenças e dos sentimentos, das estratégias de enfrentamento e das consequências percebidas na vida da criança e da família. Considerações finais: A experiência de parentalidade na situação de síndrome nefrótica da criança é caracterizada como difícil por desafiar os pais no sentido de garantir o bem-estar contínuo, promover o desenvolvimento do filho e manejar todas as mudanças nos relacionamentos e vida familiar. As categorias teóricas desveladas evidenciam a necessidade de reconhecer, nas práticas de cuidado em saúde, a experiência singular dos pais, para que a equipe de saúde desenvolva o apoio que os pais necessitam no manejo de situações complexas como o fenômeno de vivenciar da síndrome nefrótica do filho.

Descritores: Síndrome Nefrótica. Pais. Parentalidade. Doença Renal Crônica. Criança. 


\begin{abstract}
Introduction: The Nephrotic Syndrome (NS) is the manifestation of different glomerular diseases characterized by proteinuria, edema, hypoalbuminemia and hyperlipidemia. The diagnosis, the treatment and associated complications have repercussions on the child's life and the family system, demanding a high level of social, emotional and physical adjustment. The cronicity of the child constitutes an experience of parental transition that implies living with constant changes in the activities of daily life. In the situation of having a child with nephrotic syndrome, parenting is influenced and the disease is a stress factor. Thus, the objective of the study was: to comprehend the experiences of parenting in the situation of nephrotic syndrome of the child. Methodology: A cross-sectional qualitative-interpretive study developed with parents of children with Nephrotic Syndrome. Data were collected using the open-ended interview technique. Complementing the interview, the construction of the genogram and the ecomap of the family. The data were analized using the methodological framework of Narrative and Research and the interpretation was supported by the theoretical reference of Symbolic Interacionism. Results: Eight mothers and one father of children with Nephrotic Syndrome participated of the study. The main family characteristics were: nuclear families (composed of mother, father and children); degree of schooling of parents incomplete elementary school; and position of the child with NS in the family, in most cases it is the youngest son and with discovery of the disease on average at 3 years of age. The Analysis of the narratives allowed the identification of thematic categories representative of the definitions of parenting, beliefs and feelings, coping strategies and perceived consequences in the life of the child and family. Final Considerations: The experience of parenting in the child's nephrotic syndrome is characterized as difficult to challenge parents to ensure continued well-being, promote child development, and handle all changes in relationships and family life. The theoretical categories revealed the need to recognize, in health care, the experience of the parents, so that the health team develop the support that parents need in the management of complex situations such as the phenomenon of experiencing the son's nephrotic syndrome.
\end{abstract}

Descriptors: Nephrotic Syndrome. Parents. Parenting. Chronic Kidney Disease. Child. 
Sumário

1. INTRODUÇÃO9

12

12

12

3. METODOLOGIA13

3.1 CARACTERIZAÇÃO DA PESQUISA13

3.2 LOCAL, PARTICIPANTES E ABORDAGEM13

3.3 COLETA E ANÁLISE DOS DADOS 14

3.4 ASPECTOS ÉTICOS15

16

29

6. CONSIDERAÇÕES FINAIS33

34

39

8.1 Anexo I - Termo de Consentimento Livre e Esclarecido (TCLE) 39

Anexo II - Termo de Autorização para Utilização de Imagem e Som de Voz para fins de pesquisa. 41 


\section{INTRODUÇÃO}

Há várias definições de doença renal crônica (DRC), de acordo com Daugirdas (2017), ela é definida como a diminuição da função renal, com taxa de filtração glomerular estimada ajustada para a área de superfície corporal, ou lesão renal que persiste por 3 meses ou mais. A DRC é um grave problema de saúde pública, contudo, dados epidemiológicos sobre a prevalência e suas comorbidades são escassos no Brasil e no mundo. Em censo publicado em 2016 pela Sociedade Brasileira de Nefrologia, estima-se que 122.825 pacientes estão em tratamento dialítico no país, mostrando que houve um aumento nos últimos 5 anos. Destes, $1,2 \%$ tem idade menor ou igual a 19 anos (SBN, 2016).

No meio acadêmico é estabelecido que há um crescimento no número de casos de crianças com doenças renais crônicas (MISHRA et al., 2015), que os custos com o tratamento são altos (MELO et al., 2016), e ainda que existem poucos estudos sobre a compreensão da vivência da criança com insuficiência renal crônica e do significado que ela atribui a esta vivência.

Dentre as DRC se destaca a Síndrome Nefrótica (SN), que é a manifestação de diferentes doenças glomerulares caracterizada por proteinúria, edema, hipoalbuminemia e hiperlipidemia, e que acomete com maior frequência crianças menores de 5 anos e do sexo masculino. Na maioria dos casos, a família procura ajuda médica pela presença do edema, que em muitos dos casos pode ser confundido com o sintoma de alergia. Após a descoberta do diagnóstico de $\mathrm{SN}$, a família deve ser educada com relação à doença, seu manejo e sua evolução (DO LAGO et al., 2016).

As alterações que surgem com a doença não afetam somente as crianças na condição crônica, mas também seus familiares e o meio social em que vivem, já que a doença altera os relacionamentos e comportamentos de todos que convivem com a criança (SILVA et al, 2010).

O diagnóstico da Síndrome Nefrótica e suas complicações, exige tanto das crianças doentes como dos membros da sua família um alto nível de ajustamento social, emocional e físico (MISHRA et al., 2015), principalmente porque o cuidador principal assume responsabilidades de cuidado como manejo de medicação e mudança de alimentação (PARHAM, 2015), e além disso, ocorrem mudanças que alcançam praticamente todos os aspectos da vida do cuidador, incluindo seu nível de estresse, relações familiares e relacionamentos sociais (AVŞAR et al., 2015). 
Sabe-se que é crescente e expressivo o número de crianças em condição crônica e necessidades especiais de saúde que são cuidadas por suas famílias no ambiente domiciliar. Frente a isto, a dinâmica familiar é transformada, no sentido de suprir as demandas de cuidado desta criança. Nesse contexto, a vida e os relacionamentos familiares são afetados, o que tem impacto na construção da parentalidade (CASTRO; TOMAS, 2012).

A DRC tem repercussões significativas na criança e no sistema familiar, por gerar mudanças que não acompanham as transições normativas do ciclo de vida e exigências adaptativas complexas relacionadas à concepção e manejo da doença, da vida familiar e também da parentalidade. Muitas vezes, a necessidade de internações hospitalares e de cuidados constantes acaba ocasionando sofrimento e mudanças no cotidiano de todos os membros da família, principalmente do cuidador principal (DE LYRA et al., 2016). Os pais referem mudanças que alcançam praticamente todos os aspectos da vida: econômico, social, afetivo e psicológico (SILVA et al, 2012).

Conceitualmente, a parentalidade envolve um processo psicoafetivo que se desenvolve a partir do vínculo entre pais e filhos, ela é construída a partir dessa interação e envolve a aprendizagem de um novo papel - o tornar-se pais. Essa construção e reconstrução do papel parental é uma constante para o exercício da parentalidade e ocorre em meio a inúmeras transformações no ciclo e na trajetória de vida familiar (ZORNING, 2012).

A situação de doença da criança constitui uma experiência de transição parental que implica mudanças nas rotinas individuais e familiares, que são capazes de perturbar o desenvolvimento emocional das crianças e dos pais (BRÁS, 2014).

Diante dessa situação, as competências parentais e a capacidade para cuidar da criança, são desafiadas, registrando-se mudanças e alterações no cotidiano família como um todo, além da presença de estressores que podem então diminuir a capacidade de um cuidador para gerenciar adequadamente a condição crônica de seu filho (ZHANG et al., 2015).

$\mathrm{Na}$ situação de ter um filho com doença crônica, a parentalidade é influenciada de diferentes formas, a partir de como os pais definem, significam e convivem com os desafios psicossociais que acompanham a experiência de conviver com a doença crônica. Esses processos de ajustamento podem levar a desequilíbrio e maiores sofrimentos, a depender dos estilos de manejo utilizados pelos pais. O bem-estar dos pais da criança com doença crônica deve ser foco de atenção dos profissionais de saúde (CASTRO; TOMAS, 2012). 
Pensando nisso, a equipe de saúde deve examinar de perto a situação de cada grupo familiar e direcionar os recursos disponíveis para intervir em domínios específicos, orientando as famílias com vulnerabilidades e para manter o cuidado infantil normal (ZHANG et al, 2015). Tem-se argumentado que cuidadores familiares de crianças com DRC devem ser considerados como alvo de intervenção com vista a melhorar suas competências e como consequência, melhorar os resultados de saúde dos seus filhos (PARHAM et al., 2016). Pensando nisso a equipe de enfermagem deve estabelecer uma boa relação com as famílias, compreendendo-as como unidade de cuidado e não apenas como um ajudante/informante ou como um recurso em benefício da criança doente (MESZAROS; MELO, 2013).

Considerando a família como o sistema imediato de vida da criança, o olhar para cada uma das dimensões de interação familiar se faz necessário para a identificação de elementos diferenciais presentes em cada família e as possíveis influências na saúde e no bem-estar individual e coletivo.

A condição de cronicidade do filho é um fator de estresse e pode comprometer a parentalidade efetiva, a partir de sentimentos negativos que derivam na concepção de autoestima e autoeficácia parental (BRITES, 2010). Os processos de ajustamento podem levar a desequilíbrio e sofrimentos, a depender dos estilos de manejo utilizados pelos pais.

Nesse sentido, considerando-se a escassez de estudos com esse foco, torna-se emergente na pesquisa e na prática de enfermagem, ampliar a compreensão sobre as experiências dos pais, ouvir suas dificuldades e planejar intervenções para apoiá-los no exercício da maternidade/paternidade e no desenvolvimento de estratégias de enfrentamento positivas, pois se reconhece a importância de promover autonomia parental no enfrentamento, na adaptação e na integração das demandas da condição crônica da criança à vida familiar. 


\section{OBJETIVOS}

\subsection{OBJETIVO GERAL}

Compreender a experiência de parentalidade na situação de Síndrome Nefrótica da criança.

\subsection{OBJETIVOS ESPECÍFICOS}

- Descrever as repercussões da Síndrome Nefrótica na vida da criança e da família.

- Caracterizar o cuidado, o enfrentamento e os estilos de manejo parental.

- Identificar o apoio que as famílias, em especial os pais, necessitam no manejo de situações complexas, como processar, com autonomia, a parentalidade e a vida familiar diante do fenômeno de síndrome nefrótica da(o) filha(o). 


\section{METODOLOGIA}

\subsection{CARACTERIZAÇÃO DA PESQUISA}

Trata-se de um estudo de delineamento transversal e de abordagem qualitativainterpretativa.

A pesquisa transversal é aquela realizada num curto período, em um determinado momento, como o agora, que tem como objetivo produzir dados "instantâneos" da situação de saúde de um grupo com base na avaliação individual do estado de saúde de cada um dos membros deste (FONTELLES, 2009). A abordagem qualitativa busca o entendimento de fenômenos complexos e específico e em profundidade, que tem natureza social e cultural, mediante descrições, interpretações e comparações (FONTELLES, 2009).

A pesquisa qualitativa tem uma abordagem interpretativa do mundo, e estuda o sujeito em seu ambiente natural, tendo como objetivo entender os fenômenos em termos dos significados que as pessoas a eles conferem, atribuindo assim, importância aos depoimentos dos atores sociais envolvidos, aos discursos e aos significados transmitidos por eles (AUGUSTO et al, 2013).

As etapas do método de interpretação partem de depoimentos de uma pesquisa onde se observa os seguintes aspectos: leitura compreensiva, que visa a impregnação dos depoimentos, visão de conjunto e apreensão das particularidades do material da pesquisa original e que após a leitura, temas são identificados; a partir das temáticas, são recortados trechos de depoimentos e neles se identificam as ideias explícitas e implícitas; e ao final, faz-se a busca de sentidos mais amplos que articulam modelos subjacentes às ideias (MINAYO, 2010).

\subsection{LOCAL, PARTICIPANTES E ABORDAGEM}

O estudo buscou ouvir os pais da criança sobre o impacto da doença renal crônica em suas vidas e as estratégias mobilizadas para o enfrentamento e a adaptação familiar. Nesse estudo se elegeu como foco de investigação os pais de crianças com diagnóstico de síndrome nefrótica, considerando a diversidade das condições renais crônicas e as especificidades das experiências. Demais critérios de inclusão adotados foram: pais ou mães de crianças com Síndrome Nefrótica em cuidado domiciliar e acompanhamento ambulatorial; pais ou mãe de crianças com até 12 anos de idade; e participantes maiores de 18 anos de idade (inclusive ao nascimento da criança) e que tivessem condições de participar da pesquisa. 
A captação dos participantes da pesquisa ocorreu através do serviço do Ambulatório de Pediatria, vinculados ao Hospital Universitário da Universidade de Brasília.

\subsection{COLETA E ANÁLISE DOS DADOS}

Os dados foram coletados no período de dezembro de 2017 e fevereiro de 2018, utilizando-se a técnica de entrevista aberta em profundidade. A entrevista em profundidade permite a análise detalhada de determinado tópico, história ou experiência, representando um método útil para a investigação interpretativa (CLANDINIM; CONNELLY, 2000). Essa técnica metodológica que tem como objetivo acessar a narrativa dos participantes da pesquisa sobre suas experiências.

Nessa modalidade de coleta de dados o pesquisador convida o sujeito a contar a história sobre um determinado acontecimento. Para tanto, utiliza-se perguntas abertas norteadoras do diálogo e facilitadoras da narrativa. O sujeito é convidado a falar livremente sobre um tema e as perguntas do pesquisador, quando feitas, buscam dar mais profundidade às reflexões (MINAYO, DESLANDES, 2012). A entrevista aberta permite a exploração de crenças, significados e sentimentos presentes na experiência (MAYAN, 2001). Assim, a entrevista é um instrumento potente que permite ouvir, perguntar, conversar (MIGUEL, 2010). Sua escolha, nesta pesquisa, deve-se pelo fato de que as histórias que as pessoas têm para contar nos interessam quando engajamos na busca por compreender suas experiências e os significados que atribuem para essas experiências (MIGUEL, 2010).

Assim a entrevista tem início com uma ampla questão norteadora com o objetivo de obter uma narrativa ininterrupta do sujeito. Assim a entrevista teve início com uma ampla questão norteadora, "Como é para vocês ser pai/mãe do (nome da criança com síndrome nefrótica)?".

De forma complementar a entrevista, foi realizada a construção do genograma e o ecomapa, instrumentos destinados a conhecer e delinear, respectivamente, a estrutura interna e externa (rede social) da família (WRIGHT E LEAHEY, 2012). O genograma e ecomapa são instrumentos úteis e de fácil utilização. O genograma é um diagrama do grupo familiar. $\mathrm{O}$ ecomapa, por outro lado, é um diagrama do contato entre a família e o mundo (WRIGHT E LEAHEY, 2012).

Todas as entrevistas foram gravadas em dispositivo de áudio digital, para facilitar a obtenção do diálogo e para evitar a perda de dados significativos, e transcritas na íntegra. 
Para a análise dos dados optou-se pelo método da pesquisa de narrativa na perspectiva holística com ênfase no conteúdo (LIEBLICH; TUVAL-MASHIACH; ZILBER, 1998), onde os conteúdos de um relato são examinados em sua totalidade, à medida que se ocorre uma exploração dos significados implícitos e explícitos e consistiu-se em leitura continuada do material coletado com o objetivo de estabelecer um núcleo central, apontamento das impressões iniciais, especificação de conteúdos a serem seguidos na reconstrução da história, e por fim, retomada da leitura da história, destacando trechos da narrativa que retratam os temas especificados.

O processo analítico foi sustentado no referencial teórico do Interacionismo Simbólico (IS) (BLUMER, 1969; CHARON, 2004). O Interacionismo Simbólico busca conhecer os fundamentos e causas das ações humanas e concebe que o ser humano define e age na situação de acordo com significações ali estabelecidas, as quais são processadas e atualizadas na interação social (BLUMER, 1969).

\subsection{ASPECTOS ÉTICOS}

Para a garantia dos direitos dos participantes foram respeitados todos os aspectos contidos na resolução 466 do Conselho Nacional de Saúde que dispõe sobre as diretrizes para a realização de pesquisas com seres humanos (BRASIL, 2012).

A colaboração dos participantes da pesquisa na pesquisa foi formalizada através da leitura e assinatura do Termo de Consentimento Livre e Esclarecido (TCLE) (Anexo I) e do Termo de Autorização para Utilização de Imagem e Som de Voz (Anexo II).

O projeto de pesquisa foi submetido à análise do Comitê de Ética em Pesquisa com Seres Humanos (CEP) da Faculdade de Ciências da Saúde (FS) da Universidade de Brasília (UnB), bem como às Comissões de Avaliação interna do Hospital Universitário de Brasília, designado como local de estudo. O projeto de pesquisa foi aprovado pelo Comitê de Ética em Pesquisa (CEP) da Faculdade de Saúde (FS) da UnB, sob o número de protocolo $1.232 .073 / 2015$. 


\section{RESULTADOS}

Participaram do estudo 8 mães e um pai de crianças com Síndrome Nefrótica. As principais características familiares, obtidas por meio do genograma e do ecomapa, são apresentadas no quadro 1.

Quadro 1: Características das famílias dos pais participantes da pesquisa.

\begin{tabular}{|c|c|c|c|c|c|c|c|c|c|}
\hline Participante & $\begin{array}{l}\text { Idade } \\
\text { dos } \\
\text { pais }\end{array}$ & $\begin{array}{c}\text { Com- } \\
\text { posição } \\
\text { da } \\
\text { família }\end{array}$ & $\begin{array}{c}\text { Escolari- } \\
\text { dade dos } \\
\text { pais }\end{array}$ & Função dos pais & Procedência & $\begin{array}{l}\text { Idade } \\
\text { do } \\
\text { filho } \\
\text { com } \\
\text { SN }\end{array}$ & $\begin{array}{c}\text { Posição } \\
\text { da criança } \\
\text { na família }\end{array}$ & $\begin{array}{l}\text { Tempo } \\
\text { de } \\
\text { diagnós- } \\
\text { tico }\end{array}$ & $\begin{array}{c}\text { Rede de } \\
\text { apoio }\end{array}$ \\
\hline $\mathrm{P} 1$ & 29 & $\begin{array}{c}\text { Pai, } \\
\text { madrasta } \\
\text { e criança }\end{array}$ & $\begin{array}{l}\text { Ensino } \\
\text { médio } \\
\text { completo }\end{array}$ & Pintor/Autônomo & DF & 7 & $\begin{array}{c}\text { Filho } \\
\text { mais novo }\end{array}$ & 6 anos & \begin{tabular}{|} 
Vizinhança, \\
escola da \\
criança e \\
profissionais \\
da saúde
\end{tabular} \\
\hline M1 & 42 & $\begin{array}{c}\text { Mãe, } \\
\text { esposo e } \\
\text { criança }\end{array}$ & $\begin{array}{c}\text { Ensino } \\
\text { Fundamental } \\
\text { completo }\end{array}$ & Serviços gerais & Goiás & 12 & $\begin{array}{c}\text { Filho } \\
\text { mais novo }\end{array}$ & 10 anos & $\begin{array}{c}\text { Vizinhança, } \\
\text { escola da } \\
\text { criança, } \\
\text { profissionais } \\
\text { da saúde e } \\
\text { igreja }\end{array}$ \\
\hline M2 & 36 & $\begin{array}{l}\text { Mãe e } \\
\text { duas } \\
\text { crianças }\end{array}$ & Superior & $\begin{array}{c}\text { Home office/ } \\
\text { consultoria }\end{array}$ & $\mathrm{DF}$ & 11 & $\begin{array}{l}\text { Filho } \\
\text { mais } \\
\text { velho }\end{array}$ & 2 anos & $\begin{array}{c}\text { Igreja, } \\
\text { escola da } \\
\text { criança e } \\
\text { profissionais } \\
\text { da saúde } \\
\end{array}$ \\
\hline M3 & 31 & \begin{tabular}{|l} 
Mãe e 5 \\
crianças, \\
sendo 3 \\
adotadas \\
\end{tabular} & $\begin{array}{c}\text { Ensino } \\
\text { Fundamental } \\
\text { incompleto }\end{array}$ & $\begin{array}{c}\text { Dona de casa/ } \\
\text { Artesã }\end{array}$ & Goiás & 6 & $\begin{array}{c}4^{\circ} \\
\text { filho/filho } \\
\text { mais novo }\end{array}$ & 1 ano & $\begin{array}{c}\text { Ex patroa e } \\
\text { núcleo } \\
\text { familiar }\end{array}$ \\
\hline M4 & 58 & $\begin{array}{c}\text { Mãe, } \\
\text { esposo e } \\
\text { criança }\end{array}$ & $\begin{array}{c}\text { Ensino } \\
\text { Fundamental } \\
\text { incompleto }\end{array}$ & Dona de casa & Goiás & 9 & $\begin{array}{c}\text { Filho } \\
\text { mais novo }\end{array}$ & 7 anos & $\begin{array}{c}\text { Profissionais } \\
\text { da saúde, } \\
\text { religião }\end{array}$ \\
\hline M5 & 41 & $\begin{array}{c}\text { Mãe, } \\
\text { esposo e } \\
\text { criança }\end{array}$ & $\begin{array}{l}\text { Ensino } \\
\text { médio } \\
\text { completo }\end{array}$ & Dona de casa & $\mathrm{DF}$ & 10 & $\begin{array}{l}\text { Filho } \\
\text { único }\end{array}$ & 7 anos & $\begin{array}{c}\text { Igreja, } \\
\text { escola da } \\
\text { criança, } \\
\text { família e } \\
\text { profissionais } \\
\text { da saúde }\end{array}$ \\
\hline M6 & 33 & \begin{tabular}{|c} 
Mãe, \\
esposo e \\
3 \\
crianças \\
\end{tabular} & $\begin{array}{c}\text { Ensino } \\
\text { Fundamental } \\
\text { incompleto }\end{array}$ & Dona de casa & Goiás & 4 & $\begin{array}{c}\text { Filha } \\
\text { mais nova }\end{array}$ & 2 anos & $\begin{array}{c}\text { Família, } \\
\text { religião e } \\
\text { profissionais } \\
\text { de saúde }\end{array}$ \\
\hline M7 & 44 & $\begin{array}{c}\text { Mãe, } \\
\text { esposo e } \\
\text { duas } \\
\text { crianças }\end{array}$ & Superior & Professora & $\begin{array}{l}\text { Minas } \\
\text { Gerais }\end{array}$ & 9 & $\begin{array}{l}\text { Filho } \\
\text { mais } \\
\text { velho }\end{array}$ & 5 anos & \begin{tabular}{|} 
Profissionais \\
da saúde, \\
grupos de \\
apoio, \\
família
\end{tabular} \\
\hline M8 & 52 & $\begin{array}{c}\text { Mãe, } 4 \\
\text { filhos e } 3 \\
\text { netos }\end{array}$ & \begin{tabular}{|c} 
Ensino \\
Fundamental \\
incompleto
\end{tabular} & Doméstica & Goiás & 12 & $\begin{array}{c}\text { Filho } \\
\text { mais novo }\end{array}$ & 11 anos & $\begin{array}{c}\text { Profissionais } \\
\text { da saúde, } \\
\text { religião }\end{array}$ \\
\hline
\end{tabular}


As narrativas dos pais têm como núcleo central a relação parental especial construída com a criança com Síndrome Nefrótica em função das suas necessidades adicionais de cuidado e de proteção.

A análise das narrativas permitiu a identificação de categorias temáticas representativas das definições da parentalidade, que expressa o modo com conceituam o ser pai ou mãe de uma criança com Síndrome Nefrótica, das crenças e dos sentimentos e suas transformações ao longo do tempo de manejo da doença e interação com o filho doente crônico, das estratégias de enfrentamento utilizadas para manejar a situação de doença renal crônica da criança e reorganizar a dinâmica familiar e das consequências percebidas na vida da criança e da família a partir do padrão interacional e estilo de manejo adotado no processo de ajustamento familiar.

\section{Definições de parentalidade}

As narrativas dos entrevistados mostraram que a definição de parentalidade ultrapassa o foco de como é ser mãe ou pai de uma criança com Síndrome Nefrótica, mas que abrange variados temas que servem de base para definir o mesmo, como a visão de si mesmo enquanto pais de uma criança com SN, o papel e as funções que devem ser realizadas com relação ao cuidado da criança e como elas são modificadas com a presença da SN e a necessidade de uma atenção diferenciada.

Integram a experiência os desafios adicionais de cuidar de uma criança crônica, como o pai e/ou mãe enxerga as competências do cônjuge para lidar com a doença e que, por vezes é fonte de conflito, e a visão dos pais em relação ao filho doente.

As narrativas mostram que os pais enxergam como uma dificuldade ter uma criança com $\mathrm{SN}$, sendo uma luta constante manejar o cuidado específico e todas as demais demandas da criança e da família. Eles veem a si mesmos como guerreiros, pois consideram trabalhoso ter um filho com SN, principalmente pelo aumento de responsabilidade com relação ao cuidado.

Entrevistadora: "E como você se vê no papel de mãe de uma criança que tem

\section{Doença Renal Crônica?”}

"Uai menina é dificil de falar, mas eu sou guerreira, me sinto uma guerreira, falo que é nos dois, ele de um lado, eu do outro e com Deus entre os dois e na frente, nós vamos." (M4) 
"Eu acho muito chato às vezes, porque assim, eu tenho que me ocupar muito com ele entendeu, me preocupo com ele." (M8)

Ressaltam não ser fácil o papel de pais de uma criança com SN, pois várias competências precisam ser desenvolvidas. Além disso existe uma sobrecarga de sentimentos negativos e de trabalho com relação ao cuidado, principalmente por conta da dependência que a criança desenvolve e o apego que os pais têm a essa criança.

Entrevistadora: "Me conta pra você como é ser mãe de uma criança que tem uma DRC?"

"É limitado, é triste, é cansativo. Porque a alimentação tem que ser diferenciada." (M5)

"Eu fico muito feliz de ser mãe dele, apesar de todas as coisas né que acontece... Mas é bom. Eu não me vejo sem ele mais." (M4)

Declaram que há uma doação de si para com o cuidado com o filho doente, pois o mesmo precisa da presença diária e frequente dos pais, principalmente quando estão em momento de crise, ou para que não tenham uma piora da condição de saúde, exigindo muito esforço e tempo dos pais, o que pode ocasionar na desistência da realização de determinadas atividades diárias como o trabalho remunerado e as atividades de lazer.

"Tem seis anos que estamos nessa correria, vou dizer que é muito difícil. Enfim, às vezes aperta mesmo, em questão que eu moro de aluguel e de trabalhar fichado, pois eu era mais presente no hospital que no meu serviço. (...) é muita correria, corre atrás de exame, medicação. Na próxima semana, tenho que renovar a medicação dele, senão eu perco." (P1)

A visão que o cuidador tem da criança doente, também interfere na definição de parentalidade. Os pais, em sua maioria, acreditam que a criança não tem entendimento completo sobre a sua doença e que tem muita dificuldade para aceitar as mudanças de hábitos 
e rotinas que ocorreram por causa da $\mathrm{SN}$, fazendo disso um desafio adicional no desenvolvimento de competências para cuidar de uma criança crônica.

"Agora com 12 anos tá piorando né, porque ele não quer aceitar, quer comer as coisas, mas foi muito dificil até hoje, até porque ele tem crise direto." (M1)

"Questão de deixar ele sozinho, não gosto, até para se precaver também. Ficar de olho nele, direto. Ele está crescendo, está começando a dar trabalho, começando a entender as coisas também. Como ele é muito inteligente, tem que usar essa inteligência para a saúde dele também, já falei isso para ele muitas vezes." (P1)

Por outro lado, alguns pais relataram que a criança tem conhecimento sobre a sua situação e atribuem a isso o melhor enfrentamento que é promovido nas interações e comunicação que estabelecem com a criança, orientando-a sobre a doença. Algumas das crianças são mais independentes e continuam a realizar atividades diárias como ir à escola e brincar, e por isso os pais os enxergam como crianças 'normais' que muitas das vezes não aparentam ter uma condição crônica.

"Ele é muito tranquilo e eu acho que ele é uma criança de muita fé também, e isso não abala muito ele. Às vezes ele fica triste quando tem que colher sangue, às vezes em relação à comida, mas acho que isso não influencia muito não. Ele leva isso de uma forma muito madura, ele é extremamente maduro pra idade dele, mesmo porque eu sempre despertei isso nele, ele é uma criança muito madura, o foco dele não é a doença, ele nunca se importa com isso (...) Então ele já sabe tudo e não vê como algo negativo, até porque eu não deixo ele ver por esse lado. Mas eu acho que o meu papel é o principal nessa história, como eu faço ele enxergar as coisas, então eu acho ele bem tranquilo, muito estudioso, não me dá trabalho, é uma criança bem compreensiva, não tenho problema com ele.” (M2)

O aumento da carga emocional está relacionado a como cada um dois pais enxerga a criança e a visão da mãe com relação ao seu conjugue. Muitos pais não aceitam a doença da criança, criando assim um conflito entre o casal, principalmente na hora de decidir qual o melhor cuidado a ser executado, o que leva, na maioria das vezes, a mãe a acreditar que seu cônjuge/pai, não possui as competências necessárias para cuidar dessa criança. 
“(...) quando engravidei fiquei feliz, quando soube que era um menino, nossa, foi tudo. Ai depois de dois anos veio o baque... Nossa, o pai dele faltou morrer, morrer de dó, não aceita de jeito nenhum. Quando é pra vir pra cá ele já fica nervoso, aí ele fica "Ai, queria que meu filho pudesse correr, pudesse comer de tudo, pudesse sair com ele pra um lugar e dar tudo e fazer tudo" e não pode, porque quando ele vai com ele eu fico com medo, porque o pai quer dar as coisas tudo pro menino, ai eu falo que não pode." (MI)

\section{Crenças e Sentimentos}

$\mathrm{Na}$ experiência de parentalidade de crianças com Síndrome Nefrótica as crenças relacionadas à doença e à cronicidade geraram predominantemente sentimentos negativos associados às repercussões físicas e emocionais que afetam a criança e todos os membros da família. Sentimentos como pena da criança, sofrimento, desespero e incerteza relacionados ao prognóstico da doença dificultam o enfrentamento positivo dos pais. Ademais, a insegurança, a negação, a culpa, a impotência, o medo de perder o filho ou o medo de não conseguir suprir as suas necessidades especiais de cuidado e o sentimento de incompetência parental surgem a partir da crença de que não fizeram o que podiam para evitar a doença ou melhorar a saúde do filho. Todos esses sentimentos geram uma sensação de tristeza constante na vida dos pais.

O sentimento de desamparo se faz presente na experiência dos pais frente a concepção de ausência de apoio, tanto na rede familiar e de sociabilidade quanto dos serviços e profissionais de saúde.

Esses sentimentos aparecem principalmente no início da doença, quando os sintomas estão mais presentes e as crianças precisam de hospitalização para fins diagnósticos e terapêuticos. Muitos pais relatam que a descoberta da doença foi desestabilizadora, um choque, sendo prevalente o sentimento de medo do desconhecido e de desesperança.

\footnotetext{
"Quando nós descobrimos que ele tinha SN (...) foi um baque, a gente já pensa que vai ter que fazer hemodiálise, e que vai fazer transplante e a gente cria um monstro, e especialmente os pais começam a se culpar, eu achei que éramos culpados (...) A gente se pergunta o que a gente fez de errado, se a gente deixou de comer algo, se comeu algo que não deveria." (M5)
} 
A transição do início da doença (agudo) e de sua descoberta, para a situação de cronicidade é comum e perceptível a mudança de sentimentos. Nessa fase da doença sentimentos como medo e incerteza em relação ao futuro, medo da perda, medo de que a criança tenha algum trauma ou deficiência, preocupação com relação aos efeitos da medicação e curso da doença, tristeza, impotência, desespero, são fontes de sofrimento. Entretanto, apesar de vivenciarem muitos sentimentos negativos, a maioria dos pais têm esperança de um futuro melhor para seus filhos e uma melhor aceitação gradual da condição de cronicidade.

"As vezes eu fico triste né, quando ele fica na crise. Quando ele tá em crise eu já me apavoro, 'Ai meu Deus, de novo, não estou aguentando isso' sabe... Ai depois eu tento ir pro outro lado, agradeço só por ele tá aqui comigo e vivo.” (MI)

“Assim, a gente entristece um pouco porque é aquela coisa... quando a gente acha que tá tudo melhorando, vai lá e piora de novo. Mas a gente já tem uma experiência também, então fica triste mas a gente vai praquela luta de novo né, faz exame, muda mais a alimentação. A gente se baseia no que vem depois, a gente sabe que vai melhorar, que vai passar logo, e pronto, sempre foco na melhora e a gente supera rápido.” (M2)

O conjunto de crenças e sentimentos negativos nos permitem identificar as repercussões emocionais e físicas que acompanham o ser pai e o ser mãe de uma criança com Síndrome Nefrótica. Estados emocionais como depressão, baixa autoestima, perda do humor, sensação de isolamento, alterações no padrão de sono (insônia e pesadelos), nervosismo e apavoramento são evidenciados na experiência dos pais. Essa condição tem repercussões físicas como cansaço físico, dificuldade na realização das atividades diárias, inapetência, entre outros, causados pelo excesso de preocupação com a doença.

"[quando descobriu a doença] eu tinha colocado marcapasso né, não podia ficar cuidando tanto assim dele, eu sofri. (...) era dia e noite com esse menino nos braços, eu não dormia, nem de dia nem a noite, eu fazia um café, uma comida, com ele nos braços e com marcapasso e fazendo tudo isso." (M4) 
Os pais também falaram sobre suas crenças com relação à doença do filho que diz respeito as ideias e pensamentos que eles têm com relação à cronicidade e a condição de vida da criança. A partir disso, percebe-se que as narrativas trazem esse cenário crônico sendo definido como de difícil adaptação e controle, que tira a liberdade da criança e da família, fazendo a mesma ter uma vida limitada, mas que ao mesmo tempo é uma situação que necessita ser enfrentada.

“A gente fica [pensando] 'to morta de cansada, queria dá um miojo' que em 3 minutos ta pronto, mas não, eu não posso dar um miojo, tenho que preparar um bifinho, com sal e com limão no máximo (...) tudo tem que ser feito da melhor maneira, sem nada artificial, com o mínimo de sal e de óleo. (...) Com o tempo a gente sabe que vai melhorando, a gente vai entendendo que a culpa não era nossa, a gente sai do luto e vai à luta, e ai a gente vai fazer o melhor que pode e a gente sabe que passa, com as pessoas certas a gente sabe que melhora." (M5)

\section{Estratégias de enfrentamento}

As estratégias de enfrentamento são compreendidas como a forma como os pais agem na situação de ter um filho com Síndrome Nefrótica, que envolve o conjunto de significações e interações estabelecidas com a criança doente, os estilos de cuidado e de manejo da condição de cronicidade visando a integração e a adaptação às mudanças, geralmente, constantes e irreversíveis que a situação provoca na vida da criança e da família. Assim as estratégias de enfrentamento tendem a se ajustarem às necessidades da criança e dos pais, considerando-se a nova realidade de vida e os desafios transicionais que acompanham a trajetória da doença crônica. As estratégias mobilizadas, bem como a rede de apoio, podem ser tanto efetivas como inefetivas.

Dentre as estratégias de enfrentamento mais presentes e importantes quando se vivencia uma situação de doença crônica destaca-se o apoio social, que são relações existentes entre o próprio núcleo familiar (os outros filhos e o cônjuge), familiares, profissionais de saúde, vizinhança e instituições (escola, igreja etc.).

A partir das narrativas, percebeu-se que o apoio social recebido pelos pais/mães de crianças com SN é reduzido e as vezes quase inexistente, e em alguns casos o apoio social se resume apenas aos profissionais da saúde, principalmente no momento de internação, de crise e instabilidade da criança. Além desses, a família procura apoio nas instituições como a escola, 
onde a criança estuda, que é onde a família é acolhida e escutada, e a igreja, que realiza ações em prol da criança/família.

"Ninguém me ajudou não, porque quando ele adoeceu eu trouxe logo pro hospital. (...), mas assim, ninguém me ajudou nada não. Sempre foi eu que me virei, eu dou meu jeito de qualquer jeito." (M8)

"Assim, hoje nas salas, tem dois ou três alunos que fazem acompanhamento, não do mesmo caso, mas de outro né e eles tem que aceitar, eles têm que tentar fazer o melhor né. Eles sempre o incentivam [a criança doente] a tomar água." (MI)

A maioria das falas mostra que nem mesmo o núcleo familiar dá o suporte necessário para esse cuidador principal. As narrativas evidenciaram que os profissionais de saúde se tornam a principal fonte de apoio para esses pais e que estes são importantes na hora da criação de estratégias e no processo de enfrentamento, além de auxiliar na parentalidade efetiva. Mas muitas vezes, só ter como apoio médicos e enfermeiros não é suficiente, por isso é importante uma equipe multidisciplinar onde o profissional psicólogo está inserido, o qual muitas vezes pode ajudar no sofrimento psíquico que está presente.

"Eu fiz [acompanhamento com o psicólogo] quando ele ficou internado. Tinha uma sala lá, porque assim, eu fiquei muito abalada, principalmente quando eu via o estado dele, ele ficava muito nervoso. E aí encaminhou a gente e aí eu fiz. $O$ tempo que eu fiquei no hospital com ele, eu fiz acompanhamento. Eu e ele, a gente ia. (...) E Ajudou... até que ajudou. (...) porque assim, elas conversam, eu ficava o tempo todo chorando, eu tava com medo até de ter uma depressão porque lá no hospital era muito difícil, foi muito difícil. E aí elas conversavam muito comigo, falava que não era pra ter medo e que eu tinha que aprender a lidar." (M1)

Além disso, a facilidade de acesso aos profissionais de saúde em momentos de crise é considerada pelas famílias um fator positivo de enfrentamento.

"A médica é bem atenciosa, consigo falar com ela a hora que eu preciso pelo WhatsApp, então assim, tem uma assistência muito boa, por ser assim um hospital do governo e tudo, que eu sempre tive maus olhos pra isso. Então eu acho que você ter um contato com o médico pelo WhatsApp e ter a assistência que ela dá pra 
gente, eu acho que é assim... um privilégio. Não sei se todos tem, mas eu me considero privilegiada." (M2)

Foi evidenciado temas que apontam outras redes de apoio efetivas dessas famílias, ou seja, que influenciam positivamente a mesma, principalmente na hora do manejo com a doença e suas consequências. Os mais presentes nas falas foram: religião e espiritualidade, realização de atividades de lazer com a criança e a família, compartilhamento de histórias e experiências (pessoalmente com outras mães na mesma condição ou via internet), conhecimento sobre a doença, foco na melhora da condição de saúde e o próprio costume com a doença foi identificado como fator positivo para o enfrentamento.

A religião e a espiritualidade são citadas como fonte importante na hora da família/cuidador principal lidar com todo o sofrimento e com as incertezas das consequências que a doença pode trazer para a vida da criança doente. A fé de que tudo vai melhorar, ou a crença de que um milagre vai acontecer estão bastante presentes.

“Ah eu lido assim.... Confio em Deus né, por que só ele né pra poder... só ele que tem o poder né..." (M6)

Apesar da dificuldade em realizar atividades de lazer, nas narrativas, essas são citadas como ótima fonte para aumentar o apoio entre a família e consequentemente melhorar o enfrentamento, tirando o foco das dificuldades que aparecem como consequência da doença. Nas falas também apareceram a importância de se compartilhar histórias e experiências com outros cuidadores que estão passando pela mesma situação fortalecendo, assim, a rede de apoio desses cuidadores.

"[Quando surge algum sentimento negativo] Chamo o Cauã para fazer alguma coisa ou então pintar." (P1)

“Mas assim, participo de grupos na internet (...) São grupos de mães, do Brasil inteiro e lá a gente conversa sobre tudo." (M7)

A importância de se conhecer sobre a doença e entender todas as suas consequências, também foi tema das narrativas e entrou como um dos fatores determinantes para a melhoria da percepção que os sujeitos tinham sobre o contexto em que a criança com SN se encontrava, consequentemente, ajudando na superação de sentimentos negativos e conflitos. 
"Já lido melhor [com a doença] porque estudei mais, já vejo mais os casos, não é só ele. Eu imaginava assim... Nunca tinha visto falar dessa doença, aí ficava 'Só meu filho tem isso?', porque eu nunca tinha ouvido falar. E hoje não, entro na internet, pesquiso os sintomas, o que vem por conta da doença, por conta da imunidade baixa, o que causa a medicação, a reação da medicação. Sempre que ele toma remédio e sente alguma coisa eu vou lá e pesquiso se foi por conta do remédio. Hoje já é melhor, no começo foi muito dificil." (M1)

Uma outra temática presente nas falas foi o foco na melhora da condição de saúde, onde os sujeitos relatam pensar de forma positiva, além de se empenharem no cuidado à criança, principalmente com relação as mudanças da rotina diária. Além disso, a maioria dos sujeitos relataram que se acostumaram com a doença com o passar do tempo, o que os fez ter uma visão diferente com relação a mesma.

"Ele [criança doente] resistiu, principalmente com a alimentação, porque ele gosta muito de comer, salgadinho, sanduíche, isso aí ele sofreu. Mas é na conversa né, porque é sempre aquela coisa, tá ali por um tempo, mas depois ele vai poder comer. Eu sempre deixo ele comer uma vez no mês e isso consola ele, e assim, tem sempre que inventar coisa nova na cozinha... (...) Mas é aquela coisa, a gente se acostuma com tudo na vida, com doença, com a dor, tudo você acostuma e vai aprendendo a lidar...” (M2)

Além das redes de apoio efetivas, as narrativas apresentam situações de enfrentamento inefetivo. Nesse caso foram consideradas as temáticas que de alguma forma podem afetar negativamente o enfrentamento desses pais e mães, como a não aceitação da criança com relação as mudanças que ocorrem como consequência da doença levando a conflitos no núcleo familiar e o desconhecimento sobre o problema de saúde, que é um fator negativo para o enfrentamento, já que piora a intensidade dos sentimentos como incerteza e medo.

"Hoje é mais dificil por conta disso da idade, porque quando ele era menor, ele comia o que eu dava, então era melhor pra controlar porque eu não dava tudo. Hoje não, ele sabe, ele quer, vai lá e compra, vai na geladeira e pega, entendeu. Vai na casa da tia dele, passa um final de semana lá ele come, e aí é assim... (...) ele [criança] não quer aceitar, quer comer as coisas, mas foi muito difícil até hoje, até porque ele tem crise direto." (MI) 
"Abala todo mundo [a doença] né, é uma doença que a gente nem conhecia né, a gente ficava assim, pelo jeito que ele ficou [no momento da crise] ...” (M4)

Outra forma de enfrentamento que apareceu nas narrativas foi a atitude de ignorar os sentimentos negativos que surgem com a doença e comparar a situação de saúde do filho com a de outras crianças em piores condições como tentativa de alívio. Isso pode fazer com que os pais passem a não considerar a magnitude do problema, podendo haver uma diminuição da atenção e do cuidado à saúde da criança.

"Eu tento nem pensar por esse lado negativo, mulher. às vezes eu tento aí eu fico assim... 'Não, nada de negativo, vou parar de pensar nisso, vai dar tudo certo'.', (M1)

"Quando você conhece crianças mais comprometidas que o seu filho, e a gente agradece que com a gente é só isso." (M5)

Foi evidenciado nas narrativas que quando ocorre algum conflito entre os integrantes da família a estratégia utilizada para a melhora desses relacionamentos é a busca de resolução na tentativa de conciliação entre os mesmos. É importante salientar que para existir um bom relacionamento interpessoal, é necessário que a comunicação seja efetiva, para que isso ocorra, quando se percebe a existência de conflitos dentro do núcleo familiar é necessário que todos os envolvidos tentem um entendimento mútuo para superar a situação. Nas narrativas a resolução de conflitos com o cônjuge era realizado a partir de uma conversa.

"Ele [esposo] me ajuda bastante [apesar dos conflitos], até porque é só nós dois, como não tem família por perto, essas coisas, é só eu e ele. Então a gente tem que concordar, eu vou, tu vai, é assim, não tem que ir nós dois, tem que se ajudar." (M1)

Os conflitos também surgem na relação entre os pais e a criança doente. Na maioria das vezes derivados da negação da criança em aceitar as limitações impostas pela SN, com maior dificuldade, no que se refere às restrições alimentares. Nesses casos a estratégia utilizada pelos pais é a negociação.

“(...) ele gosta muito de comer, salgadinho, sanduiche, isso ai ele sofreu. Mas é na conversa né, porque é sempre aquela coisa, tá ali por um tempo, mas depois ele vai poder comer. Eu sempre deixo ele comer uma vez no mês e isso consola ele." (M2) 


\section{Consequências percebidas}

A vida da criança com SN e a vida familiar passam por importantes modificações. As consequências percebidas são as mudanças de caráter permanente, de difícil manejo ou controle. Em geral requerem constante reorganização e reequilíbrio familiar, com consequências nos diferentes domínios de funcionamento instrumental e expressivo da família.

No âmbito do funcionamento instrumental, as atividades da vida diária são transformadas de tal forma que a criança doente passa a ser o foco de toda a rotina familiar. $\mathrm{O}$ tempo familiar se torna escasso e a rotina extremamente cansativa diante da necessidade de conciliar as atividades normativas com as intensas e complexas demandas de cuidado da criança (cuidado medicamentoso, mudança e controle dos hábitos alimentares e frequentes idas ao hospital). Nesse contexto é comum a abdicação das atividades de lazer e de trabalho formal/remunerado (em especial o materno).

"Eu não trabalho fora, só em casa, (...) depois que ele [criança doente] nasceu eu não trabalhei mais, (...) era uma opção até uma determinada idade, mas então descobrimos que ele era autista e tinha $S N$, e ai... parei. (...) a gente faz um exame com o ácido todo dia, a primeira urina, e a gente vai e colhe um pouco pra fazer $e$ pra ver se ta tudo bem." (M5)

"O maior tempo é dela por que as vezes eu tenho que cuidar... quando tem que ir pra creche eu que deixo e busco, tenho que levar o lanche pra ela por que tem que ser diferente. Tenho que dar as medicações na hora certa." (M6)

Os relacionamentos e padrões de interação familiar também são modificados em consequência da vivência da situação de ter uma criança com SN. As relações mais modificadas se referem aos subsistemas: conjugal (relações e vínculos entre o casal), parental (relações e vínculos entre os pais e os filhos), fraternal (relações e vínculos entre os irmãos) e relações do núcleo familiar com a família estendida (avós, tios entre outros parentes com vínculo e proximidade).

As relações conjugais, por vezes são marcadas por conflitos e dificuldades que repercutem no cuidado também aos filhos saudáveis. A relação da mãe com os filhos saudáveis é marcada pelo distanciamento. Prevalece nos irmãos saudáveis o sentimento de ciúmes pela atenção excessiva que a criança doente recebe. Em muitas situações o irmão 
saudável também assume o papel de cuidador. Assim, a rotina diária da criança saudável também é afetada, na maioria das vezes, podendo gerar sofrimentos, conflitos e dificuldade de aceitação da condição do irmão com SN.

“Tem [conflito], com o pai dela... Por que eu dou mais atenção pra ela, não dou pros outros, ai..." (M6)

"Tenho, uma menina de 5 anos, (...) ela ajuda a cuidar dele também. Assim quando o relógio desperta no horário, ela já corre e pega o remédio dele. Mas às vezes ela sente ciúmes sim, outro dia ela chegou e disse 'mãe, adivinha, meu xixi tá espumando' e eu comecei a rir porque acontece isso com o irmão e ela falou só pra chamar minha atenção." (M2)

Outro ponto percebido foi a existência de conflito existente com a família estendida, onde o relacionamento é afetado frente a visão que esses têm com relação à criança doente.

\footnotetext{
"Os outros [família estendida] também amam, protegem [a criança] mas tem esse negócio de 'ah tadinho, ele é especial, ele é doente' e eu falo que ele não é 'DOENTE' eu não gosto que eles classifiquem ele [a criança] como coitadinho."
}

Uma outra consequência analisada foi com relação às condições financeiras que tiveram impacto tanto para as famílias que já viviam limitações, havendo uma potencialização da mesma, como para aquelas que foram geradas a partir da vivência da doença. Muitos sujeitos relataram um aumento do gasto financeiro, pela necessidade de locomoção até o hospital para realização de consultas, dívidas que apareceram pela indispensabilidade da medicação de alto custo e pela inevitabilidade de uma alimentação melhorada. Em alguns casos, o cuidador principal precisou largar o emprego para cuidar de forma integral da criança doente.

\footnotetext{
"Essa vez ele adoeceu porque o remédio acabou (...) como acabou e ela [médica] não estava aqui pra doar, aí ele adoeceu. Ficou quase um mês sem tomar remédio, minha fia, que foi dessa vez que ele adoeceu que inchou tudo." (M8)

"Até hoje eu tô devendo na farmácia, porque eu recebo auxílio do governo e não é suficiente pra colocar comida na mesa e pra comprar os remédios pra ele." (M3)
} 
"Ele [criança doente] é muito caro. (...) Mesmo tendo o apoio de um hospital que é dito como excelente, mas em emergências não é tao fácil (...) os medicamentos são caros, apesar de ter um ou outro na rede pública, não tem todos e aí a gente tem que comprar, é caro, quando o ele ta fazendo as terapias certinho, a gente gasta em torno de 2000 reais com ele ao mês." (M5)

\section{DISCUSSÃO}

A partir dos resultados dessa pesquisa foi possível identificar, como em outros estudos, que a mãe da criança com SN assume o papel de cuidador principal da mesma, ficando encarregada de todos os cuidados (PARHAM et al., 2016).

Os resultados evidenciam que a definição que os sujeitos têm de parentalidade são formados a partir de vários pontos que são percebidos na situação de doença, principalmente como eles definem ser pai ou mãe de uma criança que tem $\mathrm{SN}$, que é muito parecida com o estudo de Parham et al. (2016) que concluiu que ser pai/mãe de uma criança com DRC foi relatado como sendo uma experiência "profundamente negativa". 
A situação de doença da criança constitui uma experiência de transição parental que implica mudanças nas rotinas individuais e familiares, que são capazes de perturbar o desenvolvimento emocional das crianças e dos pais (BRÁS, 2014).

Com relação a isso foi percebido o aparecimento de uma série de estressores, que têm repercussões emocionais e físicas nesses pais, e que houve algumas mudanças a partir da descoberta da doença até o momento das entrevistas realizadas. A condição crônica requer um reajustamento e interfere diretamente na vida cotidiana, tendo relação com uma pior qualidade de vida dos pais (LAAKKONENet al., 2014).

Uma investigação que explorou as experiências dos cuidadores de crianças com DRC identificou uma multiplicidade de estressores relacionadas aos pais cuidadores, tais como má saúde física, inquietação, desamparo, incerteza, preocupação com o futuro, preocupação com o desenvolvimento de seus filhos, redução da renda familiar, redução das atividades familiares e relacionamentos, perda de contatos sociais e dificuldades associadas à complexidade do regime de tratamento da DRC (PARHAM et al, 2016).

De acordo com Zhang et al. (2015), é comum que na fase aguda da doença os pais podem acabar sentindo decepção e desamparo e muitas vezes até raiva da situação em que a família se encontra, "o momento que a família é comunicada do diagnóstico é estressante, tenso, coberto de incertezas, traz consigo medo do desconhecido, sendo muitas vezes doloroso" (COSTA et al., 2015, p. 628), já a cronicidade é um fator de estresse familiar, que pode comprometer a parentalidade efetiva, a partir de sentimentos negativos (culpa, vitimização, não aceitação, entre outros) que derivam na concepção de autoestima e autoeficácia parental (BRITES, 2010).

Além disso, percebeu-se o aparecimento das crenças relacionadas à doença, sabe-se que a percepção que os pais têm sobre a doença influencia de forma negativa ou positiva a criança, influenciando a adaptação da mesma com relação a doença. Esse modo de percepção é baseado em aspectos emocionais, que aparecem com a descoberta da doença, a convivência com a criança doente e as consequências da doença (COSTA et al., 2015).

Com relação as estratégias de enfrentamento, percebeu-se que as redes de apoio desenvolvem papel fundamental na hora dos pais/mães desenvolverem estratégias de manejo. O apoio social possibilita aos pais uma maior tolerância ao estresse familiar, ajudando-os a serem mais resilientes nos seus esforços para lidar com o aumento do fardo causado pelo dever de cuidar, pelos altos níveis de estresse percebidos, pela sensação de isolamento social, depressão e ansiedade, e a incerteza sobre o futuro (LAAKKONEN et al., 2014). 
As redes de apoio verificadas foram as famílias dos entrevistados, profissionais da saúde, e instituições como escola onde o filho estuda e igrejas. A que teve mais impacto foi a da equipe de saúde, pois os sujeitos relataram uma grande aproximação e facilidade de acesso quando ocorre algum tipo de intercorrência. O apoio de amigos, familiares ou vizinhos, beneficia os pais no manejo com a doença, prestando assistência nos mais variados casos. É comum que ocorra a diminuição da interatividade dos pais com esses sujeitos, pois os mesmos estão focados em lidar com a doença crônica da criança (ZHANG et al., 2015). No caso desse estudo foi constatado que existe uma diminuição da interação com esses sujeitos e um aumento na confiança com relação a equipe de saúde, principalmente em momentos de internação.

Pensando nisso, a equipe deve criar oportunidade para que os pais expressem as emoções que estão vivenciando, reconhecendo a avaliando as dificuldades que os mesmos enfrentam, e oferecendo ajuda, estreitando os laços com os mesmos, além de fortalecer a rede (BEANLANDS et al., 2017).

De acordo com Sluzki (2003), quando confiáveis, as redes de apoio acabam fornecendo fontes para a busca da promoção de saúde, além de servir como suporte para a melhora da situação. A rede social é entendida como as relações que a pessoa considera importante na sua vida, ou seja, suas relações interpessoais.

De acordo com Zhang et al. (2015) os enfermeiros podem orientar as famílias que estão vulneráveis e em sofrimento, tentando apontar a melhor solução para a melhora do mesmo, além de serem fonte de informação, suporte e incentivo tanto para os pacientes quanto para sua família e seu cuidador principal, além de encorajar este a gerenciar a situação.

Existem além do apoio social, estratégias que podem melhorar ou piorar o enfrentamento dos pais que estão passando pela situação de ter um filho com SN. Uma estratégia importante para a melhoria do enfrentamento é ter o conhecimento sobre a doença da criança. A falta de informações sobre a doença como a gravidade, tratamento e curso da doença, podem contribuir para o aumento da incerteza que os pais sentem com relação a mesma (BEANLANDS et al., 2017). Além disso, a criança com SN necessita que seus pais possuam esclarecimento sobre a doença, para que os mesmos possam ter papel importante no cuidado, não apenas como prestadores dos cuidados básicos, mas para ajudar a criança na superação e aceitação da condição de saúde (COSTA et al., 2015).

De acordo com Ribeiro \& Rocha (2007), a educação em saúde é importante para que a criança com $\mathrm{SN}$ e seus pais sejam protagonistas no processo de educação, fazendo com que os 
mesmos encontrem maneiras saudáveis de se conviver com a doença, evitando a negação e aceitando que a mesma tem impacto em suas vidas.

A criança com doença crônica precisa que seus pais tenham entendimento sobre a doença, terapia e as restrições, de modo que os mesmos exerçam o cuidado, não apenas como prestadores de cuidados básicos, mas também com relação à patologia para ajudar a criança durante o processo. Principalmente pelo impacto que a mesma tem na mudança de rotina, principalmente com relação a hábitos alimentares, medicamentos, consultas e exames, e cuidados como a interação social devido a baixa imunidade, que é consequência da doença (COSTA et al., 2015).

De acordo com Borges (2018), as recaídas são frequentes nessa doença, necessitando dos pais um alto gerenciamento domiciliar, com constante monitoração da urina, regime medicamentoso, e a busca de atendimento médico nos momentos de recaída em tempo hábil.

Além dessas mudanças da rotina diária, como nesse estudo, um outro identificou que como consequência da doença crônica as interações familiares foram modificadas, o que resultou na tensão entre os cônjuges, desestabilizando o relacionamento inter-parental, e também negligência com outros filhos (LAAKKONEN et al., 2014), o que faz com que o cuidador principal necessite de ajuste emocional para lidar com esses conflitos.

De acordo com Mishra et al. (2015) foi identificado que os pais relataram dívidas financeiras relacionadas com o alto custo do tratamento da criança com síndrome nefrótica. Devido as mudanças na rotina da família e a necessidade de cuidado constante do filho doente, em algumas situações o cuidador principal necessita deixar de lado o trabalho fora do lar, abandonando o emprego, ou que o mesmo tenha que negociar horários mais flexíveis com os empregadores para se ajustar ao cuidado (COSTA et al., 2015).

Apesar de todas as mudanças observadas na vida dos pais, os mesmos aprendem a lidar com a doença com o tempo (como as mães percebem). Assim, a maioria das famílias que lidam com síndrome nefrótica por mais de um ano estabilizam e se adaptam a mesma (MISHRA et al., 2015). 


\section{CONSIDERAÇÕES FINAIS}

Esse estudo concluiu que a experiência de parentalidade na situação de síndrome nefrótica da criança é caracterizada como difícil por desafiar os pais em suas crenças, concepções, competências e práticas de cuidado no sentido de garantir o bem-estar contínuo e promover o desenvolvimento do filho e manejar todas as mudanças nos relacionamentos e vida familiar.

A intensidade das demandas e a necessidade de reorganização familiar podem gerar estresse e sofrimento, em especial nos pais que precisam aprender a manejar incerteza, preocupações com o futuro, limitações nas atividades e relacionamentos familiares e dificuldades relacionadas à doença. 
As categorias teóricas desveladas evidenciam a necessidade de reconhecer, nas práticas de cuidado em saúde, a experiência singular dos pais, para que a equipe de saúde desenvolva o apoio que os pais necessitam no manejo de situações complexas, frente ao fenômeno da síndrome nefrótica do filho.

Pensando nisso, conclui-se que é necessário identificar quem são os cuidadores principais da criança com SN, pois os mesmos necessitam dos profissionais de saúde um suporte adicional, pelas consequências que a doença podem causar, comprometendo o cuidado prestado por esse cuidador.

Sendo assim, esses cuidadores devem ser alvos de intervenções realizadas pela equipe de saúde, principalmente no que diz respeito ao aumento da rede de apoio desse pai/mãe, como por exemplo, grupos de pais/mães que lidam com a mesma situação de doença do filho.

Com essa pesquisa ficou claro que existem poucos estudos que abordam especificamente a experiência que os pais têm na situação de síndrome nefrótica da criança e que é necessário a realização de mais estudos com esse objetivo para uma compreensão mais aprofundada as mudanças mais significativas que ocorrem na vida dessas famílias no sentido de elaborar modelos teóricos e abordagens de cuidado focalizadas no apoio aos pais no desenvolvimento da parentalidade efetiva.

\section{REFERÊNCIAS}

AUGUSTO, Cleiciele Albuquerque et al . Pesquisa Qualitativa: rigor metodológico no tratamento da teoria dos custos de transação em artigos apresentados nos congressos da Sober (2007-2011). Rev. Econ. Sociol. Rural, Brasília, v. 51, n. 4, p. 745-764, Dec. 2013 Available from $<$ http://www.scielo.br/scielo.php?script=sci_arttext\&pid=S010320032013000400007\&lng=en\&nrm=iso>. access on 05 June 2018. http://dx.doi.org/10.1590/S0103-20032013000400007. 
AVŞAR, U. et al. Caregiver Burden, Anxiety, Depression, and Sleep Quality Differences in Caregivers of Hemodialysis Patients Compared With Renal Transplant Patients. Transplantation proceedings, v. 47, n. 5, p. 1388-91, 2015.

WRIGHT, Lorraine M.; LEAHEY, Maureen. Enfermeiras e famílias: um guia para avaliação e intervenção na família. Editora Roca, 2002.

BEANLANDS, H. et al. Learning to live with nephrotic syndrome: experiences of adult patients and parents of children with nephrotic syndrome. Nephrology, dialysis, transplantation: official publication of the European Dialysis and Transplant Association - European Renal Association, v. 32, n. 1, p. i98-i105, 2017.

BLUMER, H. Symbolic interactionism: perspective and method. Englewood Cliffs: Prentice Hall; 1969.

BLUMER, H. The Methodological Position of Symbolic Interactionism. In: Symbolic Interactionism: Perspective and Method. [s.1: s.n.]. p. 1-60.

BORGES, K. et al. Parental Health Literacy and Outcomes of Childhood Nephrotic Syndrome. v. 139, n. 3, 2018.

BRÁS, Maria Salomé. A parentalidade positiva rumo à capacitação parental. 2014. Tese de Doutorado.

BRASIL. Ministério da Saúde. Conselho Nacional de Saúde. Resolução CNS/MS no 466, de 12 de dezembro de 2012. Diretrizes e normas regulamentadoras para pesquisas envolvendo seres humanos.

BRITES, Rute Sofia Ribeiro et al. Parentalidade, auto-estima e auto-eficácia: A situação de doença crónica de um filho. 2010. 
CASTRO, E.; THOMAS, C. Parentalidade no contexto da doença crônica infantil. Maternidade e paternidade: a parentalidade em diferentes contextos. São Paulo: Casa do Psicólogo, p. 253-268, 2012.

CHARON, Joel M. Symbolic interactionism: An introduction, an interpretation, an integration. Pearson College Division, 2010.

CLANDINIM, D. Jean; CONNELLY, F. Michael. Narrative inquiry: experience and story in qualitative research. San Francisco: Jossey-Bass; 2000.

COSTA, Wisllane Krystine dos Santos et al. Como as mães percebem seus filhos com a síndrome nefrótica. Revista de enfermagem UFPE on line-ISSN: 1981-8963, v. 9, n. 2, p. 624-632, fev. 2015.

DAUGIRDAS, J.T.; BLAKE, P.G.; Ing, T.S. Manual de Diálise. 5a. ed. Rio de Janeiro: Guanabara Koogan, 2017

DO LAGO, Patrícia Miranda et al. Pediatria baseada em evidências - Barueri, SP: Manole, 2016.

FONTELLES, Mauro José et al. Metodologia da pesquisa científica: diretrizes para a elaboração de um protocolo de pesquisa. Revista Paraense de Medicina, v. 23, n. 3, p. 1-8, 2009.

KNAFL, K. A.; DEATRICK, J. A. Further refinement of the family management style frameworkJournal of Family Nursing, 2003.

LAAKKONEN, Hanne et al. Parent-child and spousal relationships in families with a young child with end-stage renal disease. Pediatric Nephrology, v. 29, n. 2, p. 289-295, 2014. 
LIEBLICH,A.; TUVAL-MASHIACH,R.; ZILBER,T. Narrative research: reading, analysis and interpretation. v. 47; Series: Applied social research methods. Thousand Oaks: Sage; 1998.

MAYAN, María. Una introducción a los métodos cualitativos. Módulo de entrenamiento para estudiantes y profesionales. Alberta: International Institute for Qualitative Methodology, v. 34, 2001.

MELO, Ana Paula Rodrigues et al. Ações de profissionais da Estratégia Saúde da Família na detecção da doença renal crônica. Rev. enferm. UFPE on line, v. 10, n. 5, p. 1635-1644, 2016.

MESZAROS, M.J.; MELO, L.L. Vivências de familiares de crianças com insuficiência renal crônica durante a reinternação. Revista Eletrônica Acervo Saúde, v.5, n.1, p.338-358, 2013

MINAYO, Maria Cecília de Souza (org.). Pesquisa social: teoria, método e criatividade. 29. ed. Petrópolis, RJ: Vozes, 2010. (Coleção temas sociais).

MINAYO, Maria Cecília de Souza (org.);DESLANDES, Suely Ferreira. Pesquisa social: teoria, método e criatividade. 32 ed. Petrópolis, RJ: Vozes, 2012. (Coleção temas sociais).

MISHRA, K. et al. of Kidney Diseases and Transplantation Original Article The Impact of Pediatric Nephrotic Syndrome on Parents ' Health - Related Quality of Life and Family Functioning: An Assessment Made by the PedsQL 4 . 0 Family Impact Module. v. 26, n. 2, p. 285-292, 2015.

NUNES, Alia Barrios. Desenvolvimento moral: novas perspectivas de análise. Psicologia Argumento, v. 25, n. 51, p. 413-424, 2017. 
PAES DE LYRA, Fabíola Maria et al. Enfrentamento familiar: convivendo com criança portadora de doença crônica. Revista de enfermagem UFPE on line, [S.1.], v. 10, n. 8, p. 2790-2800, apr. 2016. ISSN 1981-8963. Available at: <https://periodicos.ufpe.br/revistas/revistaenfermagem/article/view/11345>. Date accessed: 09 june 2018.

PARHAM, R. et al. Development of a measure of caregiver burden in paediatric chronic kidney disease: The Paediatric Renal Caregiver Burden Scale. Journal of Health Psychology, v. 21, n. 2, p. 193-205, 2016.

RIBEIRO, Rosa Lúcia Rocha; ROCHA, Semiramis Melani Melo. Enfermagem e famílias de crianças com síndrome nefrótica: novos elementos e horizontes para o cuidado. Texto \& Contexto Enfermagem, v. 16, n. 1, 2007.

SILVA, M. A. S.; COLlET, N.; SILVA, K. L.; MOURA, F. M. Cotidiano da família no enfrentamento da condição crônica na infância. Acta Paul Enferm. 2010, v. 23, n.3; p. 359365.

SLUZKI, Carlos E. A rede Social Na Pratica Sistêmica, 2th ed. São Paulo: Casa do Psicólogo; 2003.

SOCIEDADE BRASILEIRA DE NEFROLOGIA. Amostragem dos centros de diálise do Brasil. São Paulo; 2016.

WRIGHT, L.M.; LEAHEY, M. Enfermeiras e famílias: um guia para avaliação e intervenção na família. 5.ed. São Paulo: Roca; 2012.

ZHANG, Y. et al. Identifying factors related to family management during the coping process of families with childhood chronic conditions: A multi-site study. Journal of Pediatric Nursing, v. 30, n. 1, p. 160-173, 2015. 
ZORNIG, S. A. J. Construção da parentalidade: da infância dos pais ao nascimento dos filhos. Maternidade e paternidade: a parentalidade em diferentes contextos, São Paulo: Casa do Psicólogo; 2012. Cap.1; p. 17-34.

\section{ANEXOS}

\subsection{Anexo I - Termo de Consentimento Livre e Esclarecido (TCLE)}

Você está sendo convidado para participar da pesquisa "Doença Renal Crônica da Criança e Vida Familiar: impacto nos subsistemas e padrões de enfrentamento", desenvolvida sob a responsabilidade da professora doutora Aline Oliveira Silveira. O objetivo geral deste estudo é: compreender o impacto da doença renal crônica da criança na qualidade de vida familiar e caracterizar os padrões de enfrentamento e de adaptação da criança, do irmão e dos pais.

Para a coleta destas informações será realizada uma entrevista com os pais. A entrevista terá como pergunta: contem-me como é para vocês ser pai/mãe do(a) (nome da criança com doença renal crônica)? As entrevistas serão realizadas em local privativo e o diálogo será gravado.

A participação não é obrigatória e não há influência deste estudo com o atendimento ofertado em nenhuma instituição de saúde que esta família seja atendida. A sua participação nesta pesquisa consiste em conceder a realização das entrevistas com você (pai/mãe) e as crianças pelas quais você é responsável.

Asseguramos a vocês a não identificação sua e de suas crianças, o sigilo das informações trazidas por você e pelas suas crianças na entrevista, e a possibilidade de vocês deixarem de participar do estudo a qualquer momento, mesmo após terem assinado esse termo. 
Este estudo não deve oferecer qualquer despesa ou desconforto para você. Esta pesquisa não envolve procedimentos invasivos. No entanto, entendemos que os riscos relacionados à participação nesta pesquisa estão vinculados à lembrança de experiências prévias em família. Se percebermos a necessidade de recursos para auxiliar você e suas crianças no que se refere a aspectos emocionais, iremos prontamente identificar na rede de serviços profissionais que possam dar continuidade de cuidado à situação identificada por nós.

Caso o responsável e/ou suas crianças relatarem ou manifestarem qualquer desconforto ou mal estar por ocasião das entrevistas realizadas, a entrevista será interrompida e será continuada em um outro dia, se e quando o responsável legal desejar. Caso se perceba qualquer risco ou dano não previsto, as atividades serão imediatamente suspensas.

Acreditamos que os resultados deste estudo colaborarão para compreender a experiência da família no manejo da doença renal crônica da criança, de maneira a identificar e apontar as dificuldades vivenciadas pelos pais, crianças com doença renal crônica e seus irmãos, subsidiando os profissionais da saúde na reflexão sobre a temática e na qualificação do atendimento, considerando a família como foco do cuidado. Assim, sua participação ajudará na compreensão do apoio que a família necessita para enfrentar essa situação de doença cronica na infância. Não haverá nenhum benefício direto à sua pessoa ou suas crianças.

Os dados poderão vir a ser divulgados em eventos científicos e publicações científicas. A qualquer momento estaremos à sua disponibilidade para esclarecimentos com relação à pesquisa. Em caso de dúvida ou desejo de acesso à pesquisa poderá entrar em contato com a pesquisadora responsável, que sou eu, Aline Oliveira Silveira e você poderá me encontrar no endereço Campus Universitário Darcy Ribeiro, Faculdade de Ciências da Saúde, Departamento de Enfermagem, Conjunto 4, Sala 20, Brasília, CEP 70910-900, ou nos telefones (61) 9966-3133 ou (61) 3107-1790, ou no e-mail: alinesilveira@unb.br.

Rubrica dos participantes e pesquisadora responsável:

O projeto de pesquisa foi aprovado pelo Comitê de Ética em Pesquisa em Seres Humanos da Faculdade de Ciências da Saúde da Universidade de Brasília que tem o papel educativo, de prover informações e de zelar pelo cumprimento dos preceitos éticos da pesquisa de acordo com a Resolução 466/2012 do Conselho Nacional de Saúde. Este Comitê de Ética funciona na Faculdade de Ciências da Universidade de Brasília, Campus Darcy Ribeiro, Asa Norte, Brasília/DF, CEP 70904-970. O horário de atendimento é de segunda a sexta feira das 10:00hs às 12:00hs e das 13:30hs às 15:30hs. Fone: (61) 3107-1947. Endereço eletrônico: cepfs@unb.br / http://fs.unb.br/cep/

Fui suficientemente informado (a) a respeito do conteúdo que li ou que foi lido para mim, descrevendo o estudo "Doença Renal Crônica da Criança e Vida Familiar: impacto nos subsistemas e padrões de enfrentamento". Ficam claros para mim quais são os propósitos do estudo, os procedimento a serem realizados, as garantias de confidencialidade e de esclarecimento permanentes. Ficou claro também que minha participação é isenta de despesas. Concordo, voluntariamente, em participar neste estudo, e sei que poderei retirar o meu consentimento a qualquer momento, antes ou durante o mesmo, sem penalidades ou prejuízos. Se tiver dúvidas posso entrar em contato com a pesquisadora e com o comitê de ética de pesquisa mencionado. Esse documento possui duas vias, sendo que uma ficará em posse do responsável e outra com a pesquisadora.

Assinatura do participante:

Brasília, 1 
Declaro que obtive de forma apropriada e voluntária o Consentimento Livre e Esclarecido dos pais participantes deste estudo.

Dat

Pesquisadora Responsável

Anexo II - Termo de Autorização para Utilização de Imagem e Som de Voz para fins de pesquisa.

$\mathrm{Eu}$, autorizo

$\mathrm{a}$

utilização da minha imagem e som de voz, na qualidade de participante / entrevistado (a) no projeto de pesquisa intitulado: Doença Renal Crônica da Criança e Vida Familiar: impacto nos subsistemas e padrões de enfrentamento", sob a responsabilidade de Aline Oliveira Silveira, professora vinculada ao Departamento de Enfermagem da Faculdade de Ciências da Saúde da Universidade de Brasília.

Minha imagem e som de voz podem ser utilizadas apenas para a análise das narrativas pela equipe de pesquisa e para fins de apresentação em forma de texto em publicações em revistas científicas e eventos científicos.

Tenho ciência de que não haverá divulgação da minha imagem nem som de voz por qualquer meio de comunicação, sejam elas televisão, rádio ou internet, exceto nas atividades 
vinculadas ao ensino e a pesquisa explicitadas acima. Tenho ciência também de que a guarda e demais procedimentos de segurança com relação às imagens e sons de voz são de responsabilidade da pesquisadora responsável.

Deste modo, declaro que autorizo, livre e espontaneamente, o uso para fins de pesquisa, nos termos acima descritos, da minha imagem e som de voz.

Este documento foi elaborado em duas vias, uma ficará com a pesquisadora responsável pela pesquisa e a outra com o(a) participante.

Assinatura do (a) participante

Pesquisadora Responsável

Brasília, de de 